\title{
Star Parties in Mexico extended to Colombia and China
}

\author{
Silvia Torres-Peimbert and José Franco \\ Instituto de Astronomía, Universidad Nacional Autónoma de México, México
}

The preparation for The International Year of Astronomy 2009 stirred our interest in preparing star parties in Mexico. The lunar eclipse of February 20th 2008 was the perfect event for the first massive observation in Mexico City that attracted over 25,000 people. To accompany this event there were additional attractions: a massive astronomical lecture, more than 100 telescopes were set up for people to watch the sky, exhibits of astronomical images, children hands-on projects, rock concert, dance performance, and chats with astronomers. Already in 2009 a collective program was organized to involve more than 30 sites in Mexico to hold star parties at the same time once a year. These star parties were more in the spirit of science fairs, that include lectures, astronomy exhibits, children projects, as well as concerts and other cultural displays. The scope of each one of them depended on the local support from volunteers and from the local authorities. After the International Year of Astronomy the group that organized these star parties decided to continue its activities. The main attraction in these fairs has been the opportunity to see the Moon, Jupiter and Saturn (if observable) through a telescope. For this program the presence of the amateur astronomers has been crucial. They have brought their instruments to the sites and have generously taught the public how to look through the telescopes and pointed out to the interesting features on the sky.

Since then, the program Noche de las Estrellas has grown to include a coordinated project of many sites in Mexico to hold star parties on the same night. This effort has been very successful, and been held once every year. From 2011 to 2014 the number of sites grew in number from 41 to 57 to include most of the large cities in Mexico, and some of the smaller ones. There has been an army of volunteers that have made this program possible. The total number of volunteers (or staff) has been approximately 5,000 each time. The number of telescopes involved on average has been around 1,500. And the average number of people that have attended these science fairs has been around 160,000 each time. For the last 2 years the organizing group has extended its membership to include the participation of sites beyond our country. The most recent star party, in November 2014 included Bogota, Colombia and Beijing, China. In Bogota the planetarium hosted this activity, and it was extended to visits with telescopes to 5 schools in the city; while in Beijing the planetarium received 5,200 visitors and had lectures and additional activities. 